is such a fatal trap for cherry-stones and other foreign bodies, how much more is an open loop, of the capacity indicated, likely to catch and hold all sorts and conditions of harmful and hurtful things? And will it necessitate some future operation analogous to appendicectomy for the relief of some new class of symptoms as yet unrealised and unknown? Again, what is to become of the biliary and pancreatic secretions? I confess I cannot reply to these questions, I must leave it to those surgeons to answer who are embarking on these operations with such a light heart; but these certainly are proper questions to be put and urgently require some explanation and elucidation. Mere figures can prove anything; the effects of a serious operation on the imagination of a nervous patient are so powerful and longcontinued that a considerable time must be allowed to elapse before we can admit that these apparently unscientific and illogical operations have justified their claim as serious additions to our list of justifiable and legitimate operations, and there has not yet sufficient time elapsed to show whether these patients are materially improved or not or for any length of time. It is manifestly absurd, for instance, for Dr. W. Russell" to say "that in some quarters it seems to be thought that the time is not far distant when the art of the physician will become obsolete and be replaced by the craft of the surge on," and then to try to prove that position by describing three cases :-Case 1, pyloric narrowing, gastric dilation, and ptosis; operated on August 29th (presumably 1906). Case 2, duodenal ulcer, admitted to the Edinburgh Royal Infirmary on Sept. 21st, 1906. Case 3, malignant disease at the pyloric end of the stomach, a woman admitted to the Edinburgh Royal Infirmary on August 20th, 1906. These three cases, Dr. Russell tells us with all due gravity, "made uninterrupted and rapid recoveries, and were able to return to their homes in the course of three to four weeks." This is inimitable in its way, yet the Editors of THE LANCET reproduce it for the edification of their readers without comment and therefore presumably with their approbation. As a humble student, one thirsting for information, I would like to ask Dr. Russell what he thinks will be the state of Case 3 at the end of, say, 12 months or so from the operation? whether the mere removal of the pylorus and the formation of an orifice between the stomach and some conjectural portion of the intestine is likely to benefit permanently the patient and make a sound woman of her, one capable of carrying on the functions of life comfortably and satis. factorily for any reasonable length of time? and what is to induce the lymphatic glands to refrain from reproducing the infectious material we may reasonably assume had been absorbed from the malignant disease? These questions which are evidently brushed aside as of no practical moment to Dr. Russell are of vital importance and practically unanswerable.

The writer of the article winds up by saying :-

The alarm sounded by Dr. Rigby appears to us to be a false one; and we think his paper calculated to excite a prejudice against th medical profession and against operating surgeons more especially which the facts, far from justifying, are calculated entirely to remove.

In reply to that $I$ will conclude this already too voluminous communication by a quotation from THE LANCET itself, which I could not have credited except that it is there for any of your readers to see for themselves. In a leaderette of THE LANCE's, dated Nov. 17th, 1906, p. 1380, it states :-

Mr. - resorted to a tracheotomy for laryngeal obstruction due to cancer. The operation was so urgent that he had to perform it with a penknife. The heart stopped beating and with great promptitude he opened the abdomen with the penknife, inserted two fingers, and performed massage of the flaccid heart; after four minutes the hear began to beat, artiticial respiration was performed, and natural respira tion resumed. The patient never regained consciousness but lived for about two hours.

The writer of the article in THE LANCET who visits my poor paper on the Surgeon's Power of Life and Death with such censure made no comment on the above "urgent" (sic) double operation on a moribund cancer patient. It is difficult to place the above two operations in any class, they certainly had no prospect of saving life as the patient was suffering from an incurable disease; they were not done at the desire of the patient, nor were they done for the relief of pain, as "the patient never regained consciousness"; the only object achieved, so far as my feeble powers of observation are worth anything, was that the mere vegetative

3 The LAאCet, Jan. 12th, 1907, p. 73. existence of the poor dying patient was prolonged for two hours. Cui bono?

In conclusion let me offer a word or two of advice to the writer of the article quoted. When criticising an article appearing in a responsible journal it is wise to do so in a spirit of fair play and not to misrepresent one's opponent, who is most likely only animated by a desire to ascertain the truth. It is worth while, in a just and equitable spirit, to not only defend one's own position but critically to examine and if possible refute the views of one's opponent in civil terms. This I contend the writer of the article has quite failed to attempt to do and has introduced an element of bitterness in a controversy which ought to have been conducted without any heat or animosity but with a steadfast desire to ascertain what is best for the community at large.

Feb. 4th, 1907.

I am, Sirs, yours faithfully,

JAMES A. RIGBY.

\section{THE BENEVOLENT AGENCIES OF THE PROFESSION.}

To the Editors of THE LANCET.

SiRs,-In your leading article on medical benevolent societies in the issue of Jan. 12th you call upon practitioners generally to support these societies and also suggest to the medical men residing in those counties where no such institution exists to try and get one started.

Now, Sirs, as far as I am aware no such thing exists in this county (Lancs), and I, for one, would very much like to see one instituted-for instance, on the same lines as the Society for the Relief of Widows and Orphans of Medical Men of London. Also, no doubt a large number of the poorer practitioners here, as elsewhere, would welcome such an institution as relieving them of some of what we may term the "primitive anxieties" of life; and at the same time the wealthier memhers of the profession would be willing to support it, though they would have little chance of ever needing its benefits.

You say such a society was started in Sussex two years ago, but I am unable to find the address of its secretary (as the local medical benevolent societies are not put in the Medical Directory) or I might try and get some particulars of its foundation from him. Perhaps some of your readers who possess the necessary knowledge will make suggestions as to the best method of procedure in the attempt to get such a society started here in Lancashire, especially if they be local men.-I am, Sirs, yours faithfully,

N. I. SPRIGGS, M.D., B.S. Lond., F.R.C.S. Eng.

Southport, Feb. 8th, 1907.

\section{STRYCHNINE: WHAT IS A LETHAL, AND WHAT A MEDICINAL, DOSE? \\ To the Editors of THE LANCrir.}

Sins,-Several notes have appeared in your journal and elsewhere from time to time, and some of the doses of strychnia said to have been taken with impunity have been so enormous, in one case as much as half a drachm, that the questions arise $: 1$. Is the statement true? 2 . What is the explanation? 3. Does the dose need revision and increase ? 4. Is anyone capable of eating strychnia in the same way that some of the Styrians are said to be able to eat arsenic? 5. Is idiosyncrasy common? 6. Does the habitual consumption of strychnia allow of large doses-say, of one grain or more-to be taken with impunity, and, if so, how much? 7. What would be the position of a medical man who having administered, say, one grain of strychnia, and death ensuing, he was charged with murder?

My own experience leads me to believe that the quality of the alkaloid may in many cases be responsible for the results, especially when in the form of powder. I have used strychnia for many years and 1 find that a dose of from three to seven minims of the liquor strychniæ of the B.P. strength is very well borne by adults, but the latter dose often produces symptoms similar to ptyalism, with contraction of the platysma muscles and twitching and drawing down of the oral angles. I have usually procured the strychnia in crystals and I have made my own solution. I have some strychnia by me at the I resent time, but I should hesitate to administer so large a dose as, say, one grain to anyone, inured or otherwise, unless he was a profound believer in Christian Science, when possibly (?) the circumstances might 
be entirely altered. Strychnia is said by some of our leading neurologists to be decomposed in the stomach. No doubt this is the case, but yet it is not rendered quite an inert substance even when taken by the mouth.

I have injected the nitrate of strychnia subcutaneously in doses of $I_{1}^{1} \frac{1}{0}$ th grain and I can testify that its bitter taste can be distinctly recognised in the mouth and the appetite is notably increased. It is this bitter and tonic effect that is probably one of its most valuable qualities. One grain of strychnia dissolved in 70,000 grains of water, equal to one gallon, is said to be distinctly tasted by its bitterness. In these degenerate days, when drugs are said to be entirely useless by some, I for one should be sorry to see strychnia classed as one of the effete substances. have seen poisoning by strychnia in piegnancy with violent convulsions, but without any evidence of uterine contraction. The late Dr. Ramskill used to say that he always gave very large doses of strychnia, but what this quantity was, I have never heard him say. The dose of strychnia in some of the books is from $\frac{1}{60}$ th to $1 \frac{1}{5}$ th grain, Martindale and Westcott, ninth edition, 1898 ; from 30 th grain to 1 grain, Squire's "Companion to the British Pharmacopoeia," 1874; $\frac{1}{2} 6$ th grain has poisoned a child, Taylor's "Medical Jurisprudence," 1874 ; $\frac{1}{2}$ grain has poisoned an adult, ibid. I am, Sirs, yours faithfully,

Albert S. Morton, M.D. Durh.

Putney, S.W., Feb. 6th, 1907.

\section{A CASE OF DORSAL DISPLACEMENT OF THE ARM IN VERTEX PRESENTATION.}

\section{To the Editors of THE LANCFT.}

SiRs, -In THE LANCET of Jan. 19th, p. 165, an interesting case is reported by Dr. Arthur G. Wells under this heading. We are told that from the abdominal examination the case was diagnosed as one of second position of the child, but we are not told if the internal examination confirmed this. I venture to suggest that the case might have been one of third position of the child and then the displacement of the arm is easily explained. With the sudden rupture of membranes the left hand and arm came down over the face as is not an uncommon occurrence in vertex presentation, especially with escape of excess of liquor amnii. When the head was well in the pelvis the final long rotation occurred, but the arm did not rotate with the head. The face, the side of the head, and the occiput rotated in turn under the arm, and finally the left hand and arm were to the back of the occiput and to the left side of the child's neck, distending the right side of the perineum of the mother, as was seen in the case reported.

I should be interested to hear if the vaginal examination confirmed the abdominal, or if the vertex were too high up for a definite diagnosis. Also, if it were the left arm that was displaced. Much the same difficulty might occur with extracting a head with arms extended if the body were rotated in the wrong direction. In this case the backward displaced arm could not be liberated until the head had been rotated back again.-I am, Sirs, yours faithfully,

F. E. TuRLE EVANS, L.R.C.P., L.R.C.S. Edin.

Willesden Junction, N.W., Feb. 6th, 1907.

\section{THE CURRANT AS A FOOD.}

\section{To the Editors of THE LANCET.}

SrRs, - It seems inexplainable that the medical profession generally has expressed no opinion upon the present craze for the use of currants in bread and other forms of food. At some of our principal stores currant Joaves and other forms of eatables with currants as ingredients are exposed for sale and labelled "as recommended by (bere follows the name of a well-known practitioner)." The ethics of this legend I do not now question, but $I$ think that the wholesomeness of currants as they exist in currant loaves, \&c., is a matter of opinion and calls for discussion. If the admixture of currants with bread is really a useful and nourishing form of food, good and well, let it continue; but $I$ have no hesitation in stating that currants are neither a useful nor a wholesome addition to our bread and therefore to be condemned. Anyone having experience of children and their dietetic ailments must be aware of the effect of currants upon children. The currant is not digested by children; it is usually passed whole and is the commonest cause of stomach-ache and diarrhoea after " children's parties."

How, then, has the currant attained so high hygienic fame recently? The experience of every household where there are children is against it. It is, in my opinion, wholly unworthy of such recognition as a food and is franght with danger to the gastro-intestinal tract of children especially. With adults it may be different; the very indigestibility of the currant may serve as an exciting factor to the intestine, especially the large bowel, and promote, it may be, much-needed peristalsis and laxity thereby. This seems its only virtue and if this is its chief or only function within the human economy it is well the fact should be stated. There is possibly a difference in the digestibility of currants according as they are used in bread or in a form such as obtains in, say, dumplings. In bread, by baking, the skin of the currant is dried to an extent that renders it wholly impervious to any digestive fluid ; it is possible, however, that in currant dumplings, Shelford puddings, \&c., the long boiling to which these are submitted may serve to soften the skin or by cracking it allow the contents to be extruded. By boiling currants may be rendered less indigestible but any article of diet with currants prepared by baking, as in bread and buns, or by frying, as in countess pudding, tartlets, cakes, and fritters, the currant becomes indigestible and serves not as a food but as a gastro-intestinal irritant. I write these notes in the hope that the opinions and experiences of others may be elicited.

I am. Sirs, yours faithfully,

James Cantlie, M.B. Aberd., F.R.C.S. Eng.

Harley-street, W., Feb."12th, 1907.

\section{AN IMPORTANT CORRECTION, \\ To the Editors of THE LANCEN.}

SIRS, - The Students' Union of St. Bartholomew's Hospital regrets very much that the name and address of $E$. D. Fitzgerald, M.R.C.S., of Castle Hill-avenue, Folkestone, was included in the "Obituary List of Bartholomew's Men" and published in the Students' Union Year-Book for 1906. The Students' Union wishes through your columns to inform Mr. Fitzgerald's friends and your readers generally that $\mathrm{Mr}$. Fitzgerald is alive and well and the Union hopes to be excused for any pain which has been caused by the mistake made. I am, Sirs, yours faithfully,

Feb. 7 th, 1907. S. TREVOR Davies,

\section{A CASE OF INOPERABLE CANCER TREATED WITH TRYPSIN.}

\section{To the Editors of THE LANCET.}

SIRs,-As bearing upon the case recorded by Dr. Bertram Abrahams under the above heading in THE LANCET of Feb. 9th I should be glad to be allowed to refer your readers to the notes of the following case.

On May 19th, 1906, Messrs. - agents in this country wrote to me for advice and particulars of trypsin treatment on behalf of the wife of a constituent of theirs in South America. Briefly, from the notes of the case inclosed to me it appeared that in May-September, 1904, the patient, aged 30 years, suffered from severe pain in the right breast, stomach indisposition, ill-healtb, and "neurasthenia," for which she was treated. In the latter month a small tumour of the size of a small nut was for the first time detected in the right breast which, in spite of daily injections of cacodylate of soda for some weeks, continued to grow. In December the breast and axillary glands were removed, with apparent recovery of health. In March-April, 1905, there was a return of pain and in July obvious recurrence of growth. At this time the patient placed herself under the care of a Chinese "herb doctor." The pains and swelling disappeared and she gained is pounds in weight. In October the patient had the misfortune to lose her father and to have a daughter ill with typhoid fever. The consequent anxiety, bad nights, and constant attendance on her daughter prevented her taking care of herself and resulted in relapse. In February, 1906, the pain increased in severity and sleep was impossible; small sores and excrescences appeared at the site of the operation, accompanied by great fotor. In April the sores had increased and pleuritic effusion was present. Morphia was re. sorted to in order to mitigate the pain, which otherwise was 